\title{
Corrosion of steel piling in seawater harbours
}

1 Robert E. Melchers PhD, FICE

Professor of Civil Engineering, Centre for Infrastructure Performance and Reliability, The University of Newcastle, Newcastle, Australia
2 Robert J. Jeffrey PhD

Research Academic, Centre for Infrastructure Performance and Reliability, The University of Newcastle, Newcastle, Australia


Unexpectedly high levels of corrosion of sheet and other steel piling were observed in UK harbours during the 1980s, and a phenomenon termed 'accelerated low water corrosion' (ALWC) caused considerable concern about the structural safety of harbour quays and facilities. This paper shows that the severity of corrosion of steel piling both in the tidal zone and in the immersion zone is correlated with the concentration of dissolved inorganic nitrogen (DIN) in the local seawater. In the lower tidal zone this is consistent with the thinning of piles associated with ALWC. Previously it has been shown that in the horizontal direction the ALWC phenomenon is associated with material variability. Models are developed to allow the prediction of expected average corrosion loss both in the immersion zone and for the lower tidal zone (the ALWC effect) as a function of DIN, water temperature and exposure period. Data are presented to show the relatively low beneficial effect of changes in steel composition. It is concluded that for long-term protection against corrosion reliance must be placed on protective and preventive measures.

Notation
$A$
$c_{\mathrm{S}}$
$c_{s}$
$I$
$N$
$P$
$R_{\mathrm{A}}$

$R_{\mathrm{P}}$

$r_{\mathrm{s}}$
$T$
$t$
$t_{a}$
$t_{\mathrm{e}}$

corrosion loss in ALWC zone

corrosion loss at time $t_{a}$

long-term corrosion loss parameter

mean corrosion loss in the immersion zone annual mean dissolved inorganic nitrogen concentration

mean corrosion loss in the immersion zone in nutrient polluted waters

ratio of corrosion loss in ALWC zone compared with corrosion loss in immersion zone $=A / I$

ratio of corrosion loss in ALWC zone compared with corrosion loss in immersion zone for nutrient polluted waters $=A / P$ corrosion rate

annual mean water temperature

time (years)

time for transition from phase 2 to phase 3 net exposure period $=$ actual exposure period - life of protective coating or cathodic protection

\section{Introduction}

Steel sheet piling is used in many seawater harbours and channels to retain soil and to provide structural support for decks and quays. Structural design is governed by wellestablished principles (Anon., 2008). Historically, steel sheet piling has not been given protective coatings or cathodic protection, largely for economic reasons (Breakall, 2011). Instead, reliance is usually placed on a corrosion allowance, typically in the range $0 \cdot 1-0.5 \mathrm{~mm} / \mathrm{year}$, depending on the location along the pile (e.g. BS 6349 (BSI, 2010)).

During the 1980s several cases were discovered in UK harbours of complete perforation of sheet piling in the (rarely exposed) region just below the low water tide level (Figure 1). Corrosion rates in excess of $1.0 \mathrm{~mm} /$ year were estimated. This caused considerable concern about the potential implications for structural collapse and disruption to port operations. The phenomenon was termed accelerated low water corrosion (ALWC) (Christie, 2001), and was described at an Institution of Civil Engineers conference as 'a matter of national importance' (Breakall et al., 2005). Subsequently, cases of ALWC have also been observed in other ports, including a 


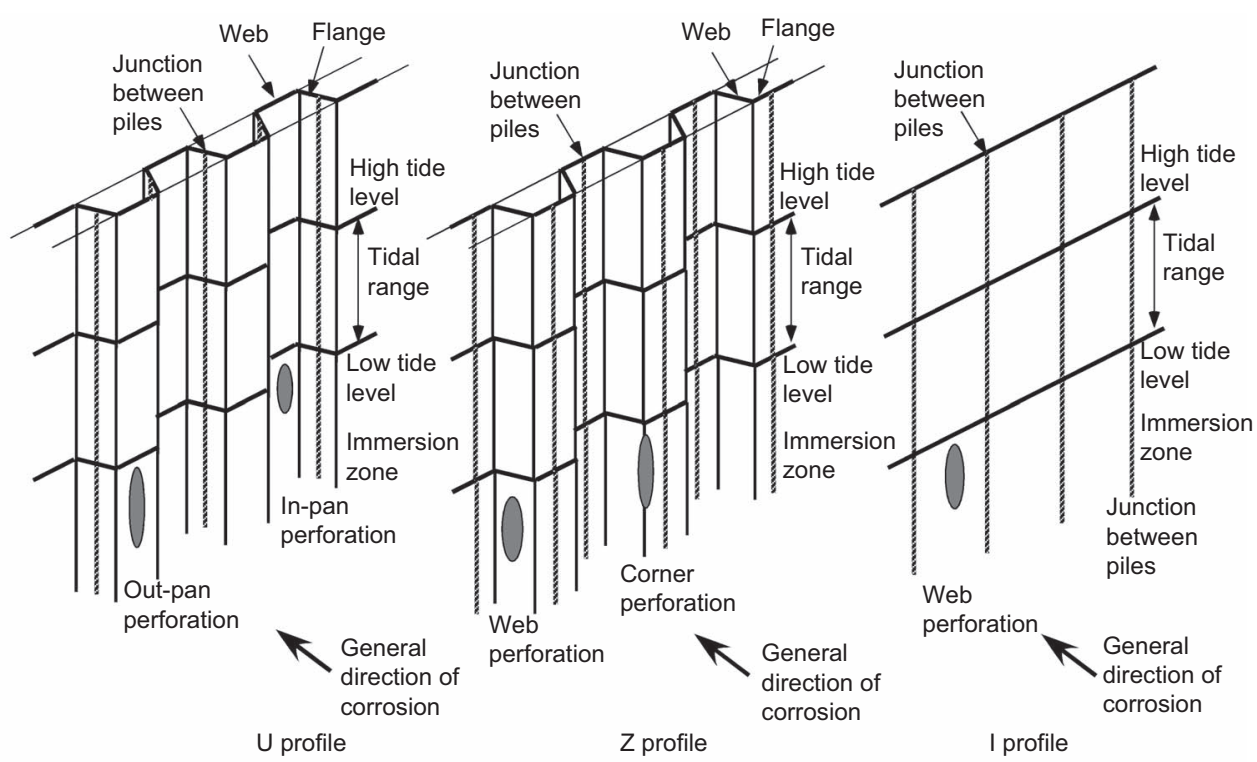

Figure 1. Schematic views of U-, Z- and I- (or straight web) profile sheet piling showing orientation of piles, high and low water tide levels and typical corrosion perforations observed under advanced cases of accelerated low water corrosion

number in France and some in Australia, Canada and the Middle East.

Interest in the corrosion of vertical (or near vertical) strips of steel through the water-air interface extends back to the pioneering work of Agar (Evans 1925), who showed that high levels of local corrosion occurred a short distance below (but not at) the water line. Studies in clean tidal seawaters LaQue (1951) and Larrabee (1958) showed that steel piles and strips corroded less in the inter-tidal zone than in the immersion zone, and that relatively more corrosion occurred in the upper tidal or splash zone. Importantly, these studies considered the corroded (vertical) profile of the steel. In contrast, ALWC is often judged simply by the perforation of sheet piling at or immediately below the low water tide level, even though it is clear that pile perforation is simply the ultimate outcome of the thinning of the pile as a result of corrosion. Perforation can thus be expected to occur at locations of greatest thinning in the vertical direction.

Field observations show that in the region just below the low water tide level not all piles in a set of piles perforate, and also that the location of perforation, where it does occur, tends to show a different pattern for the different commercial profiles of individual piles (Figure 1). Typically U-profile piles perforate on the out-pans and sometimes later on the in-pans, whereas Zprofile piles typically perforate on the webs (Figure 1). Given that perforation is the result of material thinning, this suggests that perforations correspond to areas on the pile surface or within with less resistance to corrosion than elsewhere. Indeed, recent investigations (Melchers and Jeffrey, 2013) have shown that the locations of perforation are strongly correlated with variations in material properties across the steel profile, caused by inclusions and segregation. It follows that the precise locations of perforation in the region just below the low water tide level is an effect separate to that which causes the ALWC effect in the vertical direction.

While perforation of sheet piling is important for retaining fill behind the piles, the thinning of piles and the associated loss of pile cross-section may have serious structural safety implications. This is because loss of steel profile in the vertical direction determines the (vertical) bending strength of piles, their soil retaining capacity and the operational capacity of the sheet piling system. For this reason the main focus of the present paper is the vertical corrosion effect (thinning) for steel piling. Figure 2 shows an example of corrosion losses as a function of elevation and tidal range. Typically, where ALWC occurs corrosion losses are low in the atmospheric zone (top) then high in the splash zone, lower in the inter-tidal zone and then higher just below mean low tide (MLT) level before settling down to an almost uniform amount in the immersion zone. The high corrosion (marked A) is here considered as that caused by ALWC. As noted, this effect is distinct from any horizontal effect caused by material properties. 


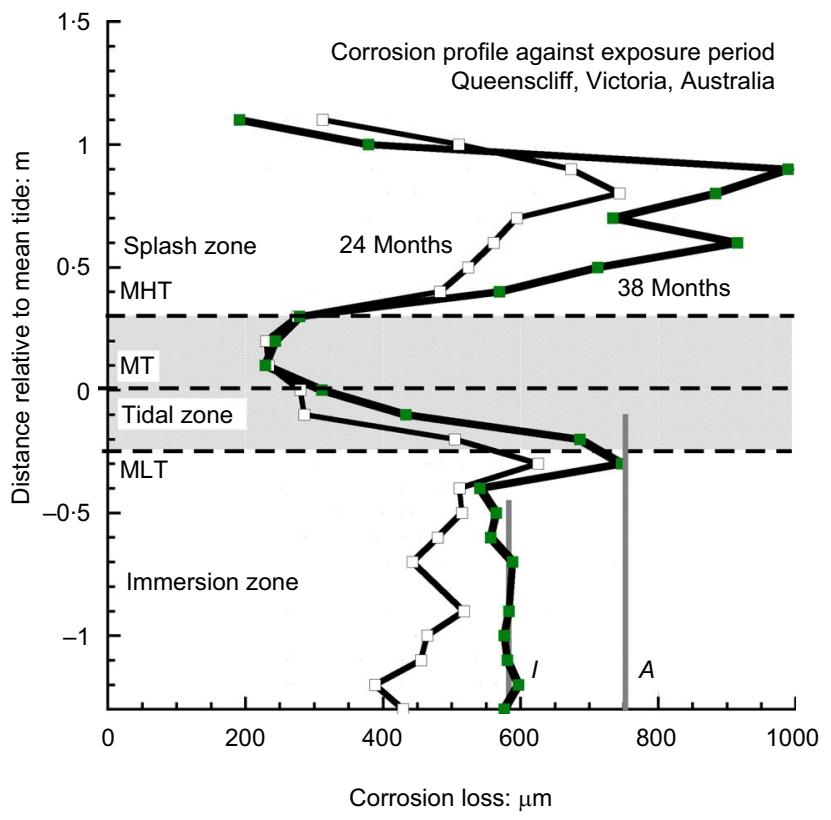

Figure 2. Examples of corrosion profiles, for 24 and 38 months' exposure obtained from mass loss measurements, showing accelerated corrosion effect $(A)$ and immersion corrosion ( $I)$. Note that each profile is from a separate sample steel strip recovered at the time shown. In accordance with standard corrosion testing protocols it is not re-used. This may account for some later corrosion being equal or even somewhat lower than earlier corrosion at the same elevation. MHT, mean high tide; MLT, mean low tide; MT, mean tide

In Figure 2 the tidal zone is shown for convenience as between mean high tide (MHT) level and MLT levels. It is therefore an average tidal zone. Actual tidal ranges do vary throughout the year and maxima and minima may occur well outside the mean tidal levels MHT and MLT. However, as corrosion is a relatively slow process compared to tidal variations, it is sufficient to consider only average tide levels. In this paper the usual mean tidal levels MHT and MLT are used.

Figure 2 shows the profiles of corrosion loss for steel strips extending in a continuous manner through the tidal zone. Quite different corrosion profiles are observed for isolated steel coupons or small plates, not connected together electrically and exposed vertically one above. The corrosion profiles for isolated steel coupons show corrosion loss to be most severe in the tidal zone, greater than in the immersion zone but sometimes a little less than in the splash zone (Larrabee, 1958; Schumacher, 1979). Unfortunately, the majority of reports of longer-term corrosion in field exposure conditions have referred only to the results for coupons, thereby giving the impression that the tidal zone is the most corrosive. As illustrated in Figure 2 this is not the case for continuous strips or electrically connected coupons in the (near) vertical direction.

As noted, ALWC is often considered a relatively recent phenomenon. This is reflected, for example, in the literature dealing with the corrosion of steel piles in tidal seawater exposures (Humble, 1949; Larrabee, 1958; Schumacher, 1979). These do not show the high, very localised corrosion in the region just below the low water tide level (A in Figure 2). As is now easily verified, the results reported in the early literature for the corrosion of steel piles were obtained mainly in clean seawater. However, there were observations, now recognisable as equivalent to ALWC - for example, for steel piles in Danish harbours with water pollution caused by fish processing (Arup and Glantz, 1963).

Early in the investigations of ALWC the involvement of microbiologically influenced corrosion (MIC) was suspected (e.g. Beech and Campbell, 2008; Breakall et al., 2005). The potential for microbiological (bacterial) activity to influence the corrosion of steel in natural environments such as seawater has been recognised for a long time. However, detailed understanding, largely obtained from laboratory studies, is more recent. In summary, steel surfaces tend to be colonised very quickly after exposure by biofilms that then allow various types of microorganisms to settle (Little and Lee, 2007). The biofilm provides a degree of shelter for microbial communities in which, under suitable conditions, individual microorganisms can flourish and directly or indirectly contribute to corrosion. Under field conditions many types of bacteria and certain archaea may be involved (e.g. Little and Lee, 2007). However, most microbiological research related to corrosion has focussed on the obligatory anaerobic sulfate reducing bacteria. These influence corrosion through their aggressive metabolic product hydrogen sulfide. It forms hydrosulfuric acid in water and this is highly corrosive to steel (Crolet, 1992).

Microbiological activity is known to be stimulated by light and ultraviolet (UV) radiation, particularly in relatively shallow waters (Little and Lee, 2007). If these were major influences on ALWC a geographical preference for regions with extended light and intense UV radiation would be expected. However, at present no such preference has yet been reported.

Microbiological metabolism requires the availability of nutrients, including organic carbon, sulfates and phosphates. These and many others are readily available in seawater. The nutrient usually inhibiting microbial metabolism in seawater is iron (Martin et al., 1994) but under corrosion conditions it is supplied by the electrochemical anodic reaction. The nutrient that then becomes rate controlling for MIC of steel is dissolved inorganic nitrogen (DIN) (Melchers, 2005). DIN is usually composed mainly of nitrates and is largely the result of 
anthropological water pollution such as from fertiliser run-off and from sewage treatment plant effluents discharging to coastal waters (OSPAR, 2000). Laboratory experiments have shown that trace amounts can affect microbiological activity and this is correlated with higher rates of corrosion of steel (Lee et al., 1995; Little and Lee, 2007). These trace amounts are too low to have a direct effect on the purely electrochemical corrosion processes. Similar correlation, but under field conditions, has been noted both for short- and for longerterm exposures of steel (Melchers, 2005, 2007a, 2007b). In contrast, an extensive field study in 22 UK harbours of the occurrence of ALWC for steel sheet piling and possible correlation with nutrients proved inconclusive (Gubner and Beech, 1999). In retrospect this is likely to be because only piles with perforations were considered to be affected by ALWC measurements of corrosion profiles were not considered.

Corrosion profiles were considered in detail in a recent, specially designed, seawater exposure study of steel strips exposed at 13 different locations on the east coast of Australia (Melchers and Jeffrey, 2012). The profiles showed clear evidence of ALWC after only 2-3 years' exposure (Figure 2). Also, correlation was established with the concentration of DIN measured near the steel strips. A subsequent study of the corrosion of steel piling exposed for 20-27 years at eight different US Navy bases and at several other US locations extended the correlation (Melchers, 2013). In both studies relatively more severe corrosion was noted in the region just below low tide level compared to corrosion in the immersion zone (Figure 2), and this increased as the concentration of DIN in the local bulk seawater increased. Although not considered in these two studies, corrosion in the immersion zone, well below low tide level, also increased. For the practical design of steel piling without protective measures corrosion both in the immersion zone and in the ALWC zone are relevant and must be considered. How these might be estimated is the subject of the present paper.

The next section provides a succinct overview of the recent findings for the vertical profile effect caused by ALWC. A multiplication factor $R_{\mathrm{A}}$ gives design guidance for how much additional corrosion can be expected in the zone below the low tide level compared to corrosion in the immersion zone, as a function of the local bulk seawater DIN concentration. The following section focuses on the corrosion to be expected in the immersion zone as a function of water temperature and DIN concentration. This requires a brief review of modelling developments for longer-term corrosion of steel in seawater and the derivation of a simplified model for practical applications, including the parameters that describe it. A range of field observations is then used to derive the model parameters and relationship to DIN as functions of seawater temperatures. A simple example is given to illustrate the concepts and the estimation of immersion corrosion and the likely severity of ALWC, both as functions of exposure time.

\section{Vertical corrosion profiles}

The severity of the vertical corrosion effect caused by ALWC and its relation to DIN concentration for steel piling in seawater was investigated using exposure tests conducted on the east coast of Australia. Mild steel strips $(50 \times 3 \mathrm{~mm}$ crosssection and 3 or $6 \mathrm{~m}$ long, depending on tidal range, exposed both sides) were suspended from a timber jetty at each of 13 different exposure sites, all in sheltered locations with minimal wave action and low (tidal) water currents. The strips were exposed to the complete tidal range, with the lower part always immersed. Typically, the strips were recovered after 1, 2 and 3 years' exposure. They were not re-used. The profile of each recovered strip was quantified (Figure 2) using mass loss measurements on $100 \mathrm{~mm}$-long segments (Melchers and Jeffrey, 2012). For each recovered strip the corrosion losses in the region below MLT, denoted $A$ and in the immersion zone, denoted $I$ were identified (Figure 2), and the ratio $R_{\mathrm{A}}=$ $A / I$ was determined to quantify the (vertical) ALWC effect. As both $A$ and $I$ are influenced by the same (or very similar) local water temperature it is reasonable to assume that $R_{\mathrm{A}}$ does not depend on water temperature (Melchers and Jeffrey, 2012). Table 1 shows the results. Local water quality was measured three to four times per year at each site throughout the study period. The estimated annual mean values of DIN are shown in Table 1.

Corrosion loss data were also available for sheet piling located at eight different US Navy bases (Brouillette and Hanna, 1960), at three US test sites (Escalante et al., 1977; Kumar et al., 1981) and also for piling (and for isolated coupons) exposed at Kure Beach (Humble, 1949) and at Harbor Island (Larrabee, 1958). Details of the sites and the measurement of the corrosion losses at these sites are available in the original references, but suffice to note all exposures were in relatively sheltered waters with low wave action and not subject to high water currents. The corrosion loss results were converted to corrosion profiles and estimates made of $A$ and $I$. As water quality parameters were not reported in the original sources, US Environmental Protection Agency (EPA) and other records were searched, for each site, to estimate the likely DIN concentration, on average, to which the sheet piling had been exposed (Melchers, 2013). The results for $A, I$ and DIN are summarised in Table 1.

Finally, some information, of varying quality, was recovered from some other sources and subjected to the same treatment as before (Melchers and Jeffrey, 2013). This included sheet piling in Tokyo Bay and Yokohama Port exposed for 11 years to high DIN concentrations, Trondheim harbour for 26 years, Port Adelaide for 52 years and Newcastle-upon-Tyne for 89 years, 


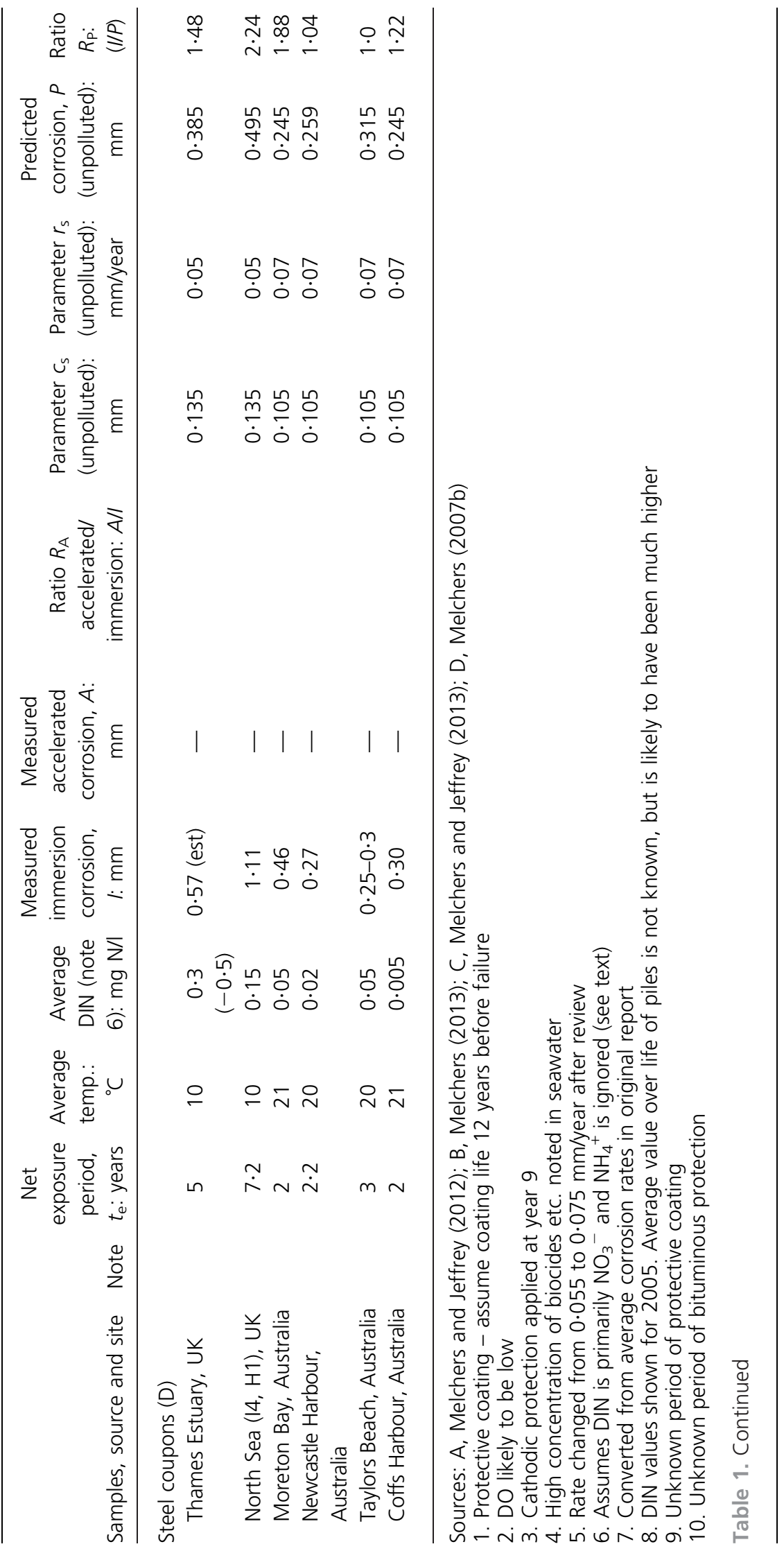


although in the latter two cases protective coatings appear to have been used originally. Again, these sites were all in relatively sheltered waters and subject only to low wave action and low water currents. Considerable effort was expended in attempting to obtain estimates of DIN throughout the exposure period, but the quality of the information obtained is not high. The results are shown in Table 1 as 'Other sheet piling'.

Figure 3 shows the estimates for $R_{\mathrm{A}}$ plotted against the average DIN concentration for each of the sites in Table 1. The trend line shown on Figure 3 is through the Australian and US data. Because of the uncertainty in the data for the remaining sites ('Other sheet piling') each is shown with an ellipse to give a (subjective) indication of the uncertainty in the estimates for $R_{\mathrm{A}}$ and DIN. Despite these uncertainties, the locations of the ellipses are generally consistent with the extrapolated trend line derived from the experimental and US observations.

The importance of the trend in Figure 3 is that it shows consistency in the parameter $R_{\mathrm{A}}$ for quite short-term exposures and longer-term exposures. It also shows that $R_{\mathrm{A}}$ is not a function of pile profile, because $\mathrm{U}, \mathrm{Z}$ and I profiles as well as strips are included in the samples in the analysis. The practical

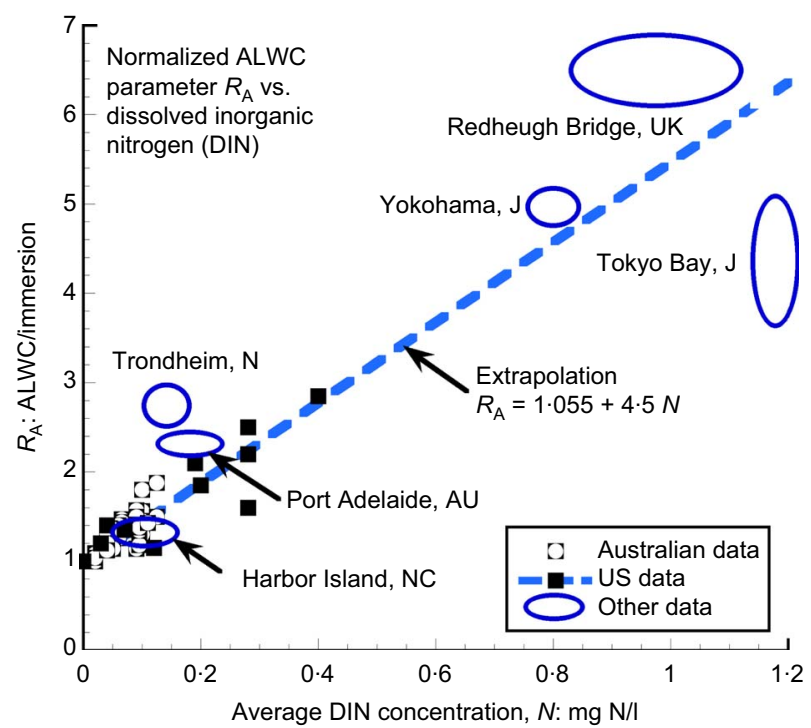

Figure 3. Correlation between accelerated low water corrosion (ALWC) parameter $R_{\mathrm{A}}$ for the accelerated corrosion of steel piling and steel strips and estimated annual mean concentrations of dissolved inorganic nitrogen (DIN) in the local seawater. The size of the ellipses represents a subjective estimate of the uncertainty in the estimates for DIN (horizontal) and $R_{\mathrm{A}}$ (vertical) (Melchers and Jeffrey, 2013) implication is that an indication of the possibility of ALWC and its potential severity $(A)$ relative to immersion corrosion $(I)$ can be obtained from knowledge of the average concentration of DIN at a site, or from relatively short-term (2-3 years) test exposures of steel strips at a site. This allows relatively early prediction of the potential of ALWC without the need for long-term exposure results.

The remaining question is how much immersion corrosion (i.e. $I$ ) is likely to occur. Once this is known, $A$ can be estimated from $A=R_{\mathrm{A}} I$. An assessment can then be made of a sacrificial corrosion allowance appropriate to the design requirements and the target life expectancy for the structure. Estimating the likely magnitude of immersion corrosion $I$ for some defined lifetime is addressed below, based on knowledge of the expected environment (including water quality and water temperature) at a given exposure site.

\section{Immersion corrosion}

To make an estimate of $I$ as a function of environmental conditions it is appropriate to review some of the more recent research findings in this area. A major reason is that the concept of a 'corrosion rate', widely used in engineering, and widely quoted in text books, corrosion handbooks and codes of practice, is usually misleading, particularly for the long-term exposures of interest to structural engineers. This can be seen in Figure 4. It shows corrosion loss data, for mild steel coupons, as observed in the Panama Canal zone (Forgeson et al., 1960; Southwell et al., 1958) over various periods of exposure to a

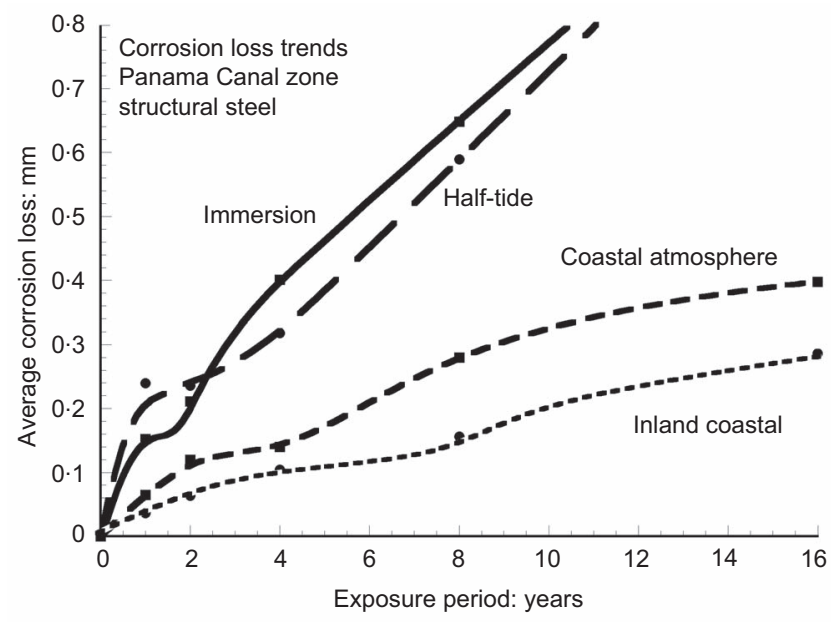

Figure 4. Data and corrosion loss trends obtained in the Panama Canal zone region for immersion, half-tide, marine coastal and inland coastal exposures showing in each case the non-linearity of the corrosion loss trends. Based on data reported by Southwell et al. (1958) and Forgeson et al. (1960) 
maximum of 16 years. Curves have been fitted to the data using the Stineman function (Stineman, 1980). It is evident that the curves are not consistent with a linear function through the origin, as required by an average 'corrosion rate'.

In some sections of the corrosion literature the non-linearity has been recognised and a simple power law adopted: $c(t)=A t^{B}$ where $c()$ is corrosion loss as a function of exposure time $t$, and $A$ and $B$ are constants obtained by fitting the function to data (e.g. Dean and Reiser, 2002). While this function is a reasonable approximation for short-term exposures (say 1-2 years), and thus covering the early part of the curves in Figure 4, for longerterm exposure data the values of $A$ and $B$ are not constant and can vary significantly with the length of the data base (Hou and Liang, 2004; Melchers, 2010). This causes instability in predictions and is thus unsuitable for practical applications.

A considerable improvement to modelling the progression of corrosion, including immersion corrosion, was achieved using the model shown in Figure 5 (Melchers, 2003a). It is for socalled 'uniform' or general corrosion derived from mass loss. It has been shown to apply also to the progression of maximum pit depth (Melchers, 2004a), as would be expected from the intimate relationship between pitting and general corrosion (Evans, 1960). Localised corrosion and pitting in the immersion zone are not considered here, although it is recognised that there are some cases when it has been reported as severe (e.g. Breakall et al., 2005). The model in Figure 5 is consistent with corrosion science principles and consists of a number of sequential phases, each representing a different stage in the corrosion process. Mathematical expressions have been developed for the most significant parts of the model (Melchers, 2003b; Melchers and Wells, 2006) but ultimately the model components must be calibrated to real-world data (e.g. Melchers, 2003b). In this sense the model is 'semi-empirical'.

It has long been recognised that the progression of corrosion with time depends on a number of factors, including water temperature, water dissolved oxygen concentration, microbiological activity as influenced by the availability of critical nutrients, water velocity and steel composition (Table 2) (Melchers and Jeffrey, 2008; Schumacher, 1979). The influences in most cases are complex and interrelated. However, for practical application many factors can be considered in isolation, provided it is recognised that the result will be a probabilistic model that recognises uncertainty in input variables as well as modelling error (Melchers, 2003c). Taking this engineering approach, a number of individual factors have been considered. However, for the case of clean natural coastal seawaters, most factors have only a relatively small effect. The two important factors are water temperature and nutrients, the latter usually being the result of water pollution (Melchers and Jeffrey, 2008). (a)

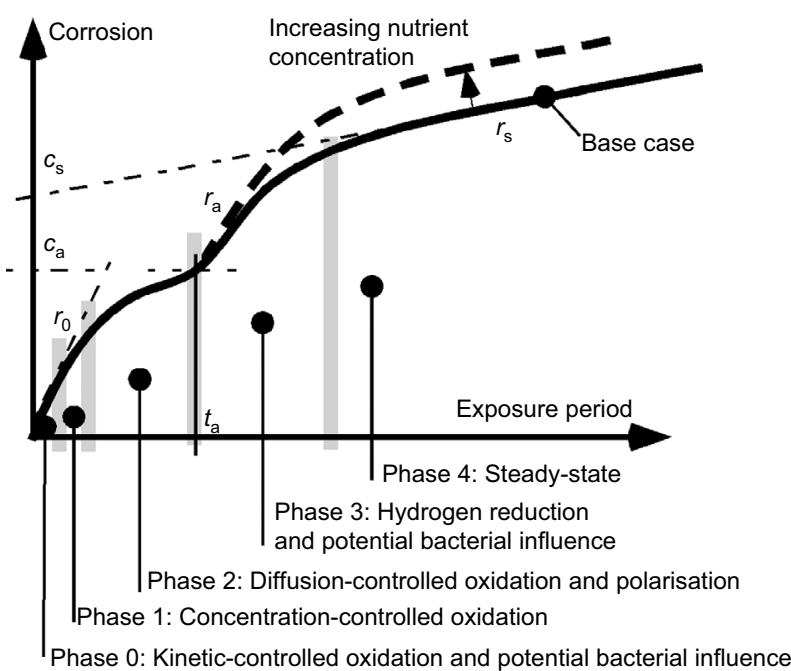

(b)

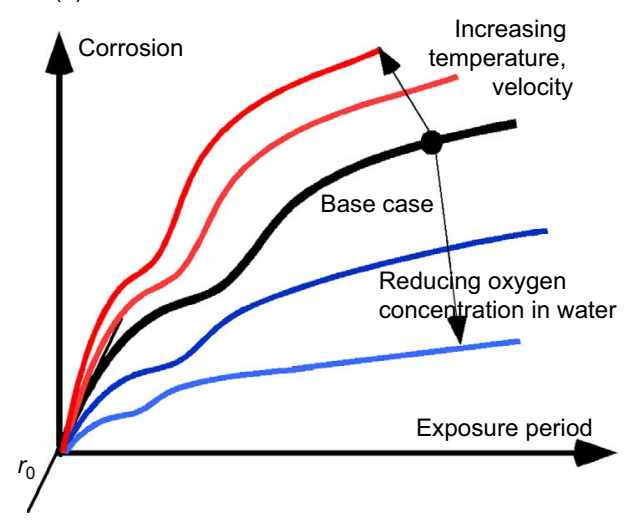

Figure 5. Schematic representation of (a) the sequential phases through which marine corrosion loss progresses and the model parameters for the base case of corrosion of mild steel in unpolluted natural coastal seawater and the effect of water nutrient concentration on microbiological activity and thus on longer-term corrosion loss; (b) the effects of seawater dissolved oxygen concentration, increased water temperature and increased water velocity (Melchers and Jeffrey, 2008) 
Influence

Potential importance

Bacteria, microorganisms

Biomass

Nutrients

DO

Carbon dioxide

Salinity

$\mathrm{pH}$

Carbonate solubility

Pollutants

Temperature

Pressure (depth)

Suspended solids

Wave action

Water velocity

DO, dissolved oxygen

Table 2. Summary of potential influences on marine immersion corrosion of steel

For longer-term corrosion the earlier part of the model (i.e. phases $0-3$ ) is of limited interest and the model may be simplified (Figure 6) to a linear function that does not pass through the origin (as would be the case for the conventional



Figure 6. Bi-linear model for long-term corrosion loss showing the linear long-term corrosion rate $r_{\mathrm{s}}$ starting from the intercept $c_{\mathrm{s}}$ and the relationship to the bi-modal model in Figure 5. Both parameters are functions of average seawater temperature, nutrient concentrations and other influences 'corrosion rate'). It is defined by the parameters $c_{\mathrm{s}}$ and $r_{\mathrm{s}}$. For unpolluted and aerated coastal seawaters under low water velocity and infrequent wave action and with other aspects typical for such waters, these two parameters are primarily functions of mean seawater temperature (Melchers, 2003a; Melchers and Wells, 2006). This simplified model is valid for exposures in excess of about $2 t_{\mathrm{a}}$, where $t_{\mathrm{a}}$ is shown in Figure 5 .

As for ALWC, MIC can have a major influence on the severity of immersion corrosion of steels exposed to seawater (Beech and Campbell, 2008) and like ALWC is a function of the availability of DIN (Figures 5 and 6). As noted, the DIN must be available to the microorganisms involved in corrosion and located close to the corroding surface and, for longer exposures, located well within the rust layers (Jeffrey and Melchers, 2003). This means that to reach the microorganisms the DIN must diffuse through the rust layers. As these become thicker and perhaps less permeable with time, the rate of diffusion will decline, and will be lower for older thicker rusts than for new rusts. As a result, for a given concentration of DIN in the bulk water their effect on MIC is likely to be lower for long-term exposures (Evans, 1960; Melchers and Wells, 2006).

\section{Effect of nutrient concentration on immersion corrosion}

The data in Table 1 may be used for quantification of the relationship between steel corrosion and nutrients, and in particular DIN. A key observation is that the immersion corrosion loss of steels for individual, electrically isolated coupons is very similar to that for the immersed part of continuous vertical steel strips (Larrabee, 1958; Schumacher, 1979). The corrosion losses for strips and coupons in the immersion zone are, therefore, directly comparable.

In Table 1, for each site (column 1), column 3 shows the net exposure period $t_{\mathrm{e}}$ and column 6 the corresponding measured or reported corrosion losses for waters having average DIN concentrations shown in column 5. To estimate the corrosion loss effect caused by DIN, corrosion losses for unpolluted waters are required for all sites. These are estimated with the simplified model for normal unpolluted coastal seawaters (Figure 6) using parameter values $c_{\mathrm{s}}$ and $r_{\mathrm{s}}$ (columns 9 and 10, respectively). The predicted corrosion loss $c$ () for nominally unpolluted sites is then obtained from $c\left(t_{\mathrm{e}}\right)=c_{\mathrm{s}}+t_{\mathrm{e}} r_{\mathrm{s}}$ (column 11). This is compared with the corrosion loss under nutrient conditions (column 6), expressed as the ratio $R_{\mathrm{P}}$ (column 12). Note that the net exposure period $t_{\mathrm{e}}$ relevant for the present analysis is the period of time for corrosion of steel unprotected by paint or similar coating or by cathodic protection.

Figure 7 shows ratio $R_{\mathrm{P}}$ as a function of the average DIN concentration. The data fall into two quite distinct groups short-term exposures, mainly 2 years and some up to 5 years, 




Figure 7. Data and trends for the ratio $R_{\mathrm{p}}$ as a function of the average dissolved inorganic nitrogen concentration. There are two groups of data, for short-term exposures and for long-term exposures

and much longer exposures, around 20 years on average. This reflects that for short-term corrosion the rust layers tend to be thin and immature rusts, and this permits a relatively higher rate of diffusion of nutrients from the bulk water to the corroding surface compared to the rate of diffusion possible with more mature, thicker, denser and less permeable rusts present after long exposures. The trend lines are reasonable fits to the data, despite considerable scatter. This is inevitable, however, because the data were obtained from similar but different, uncontrolled experiments (Lee et al., 2010).

The trends in Figure 7 allow estimates to be made of the changes in $c_{\mathrm{s}}$ and $r_{\mathrm{s}}$ with an increase in average water temperature. This is shown in Figures 8 and 9 for average values of $c_{\mathrm{s}}$ and $r_{\mathrm{s}}$. Both figures should reflect the scatter in the results shown in Figure 7 - an approximate analysis indicates that in each case most of the scatter lies in the range $\pm 25 \%$.

\section{Example}

An estimate for the effect of nutrient pollution on longer-term corrosion of sheet piling and the effect of ALWC can be made if the annual average seawater temperature $T_{\mathrm{s}}$ is known or can be estimated for the location of interest. For example, consider a steel structure exposed to North Sea waters ( $T$ around $10^{\circ} \mathrm{C}$ on average) for a period $t_{\mathrm{e}}=20$ years. The simplified corrosion loss model (Figure 6) requires values of $c_{\mathrm{s}}$ and $r_{\mathrm{s}}$ corresponding to $T$. These can be read from Figures 8 and 9 and substituted

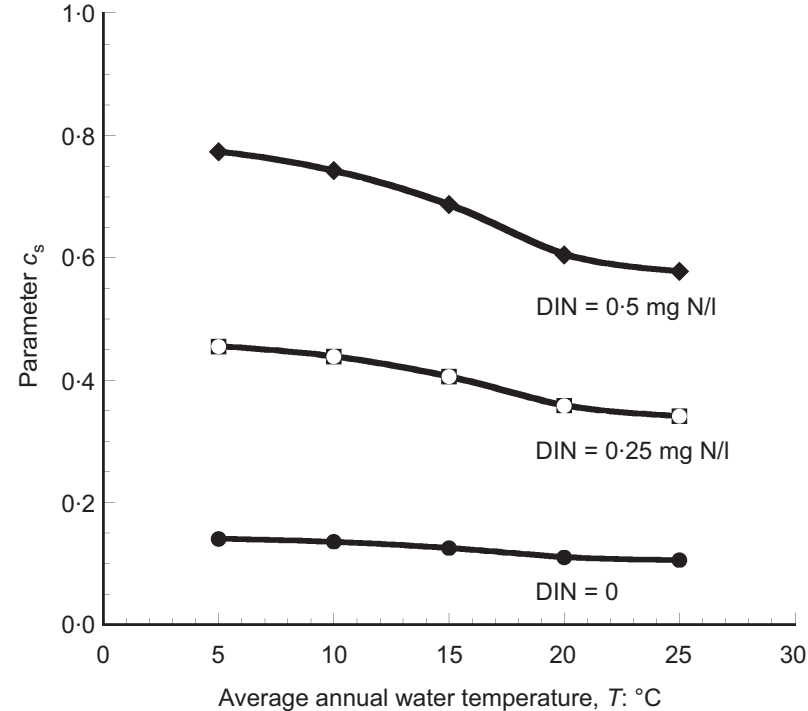

Figure 8. Average values of parameter $c_{s}$ as a function of average annual water temperature for different dissolved inorganic nitrogen (DIN) values

in $c\left(t_{\mathrm{e}}\right)=c_{\mathrm{s}}+t_{\mathrm{e}} r_{\mathrm{s}}$ to obtain the corrosion losses $c()$ at $t_{\mathrm{e}}=0$ and 20 years. This corresponds to the straight line for DIN $=0$ in Figure 10. A simple calculation shows that it has a slope of $0.05 \mathrm{~mm} /$ year. Similar straight line corrosion loss trends can be obtained for waters with nutrient pollution, with the upper and

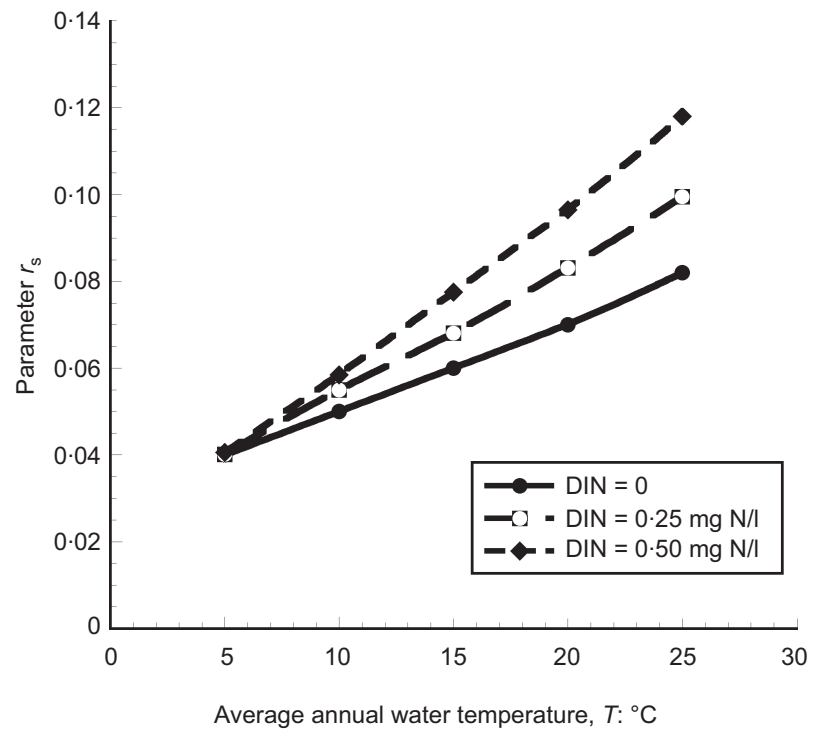

Figure 9. Average values of parameter $r_{\mathrm{s}}$ as a function of average annual water temperature for different dissolved inorganic nitrogen (DIN) values 


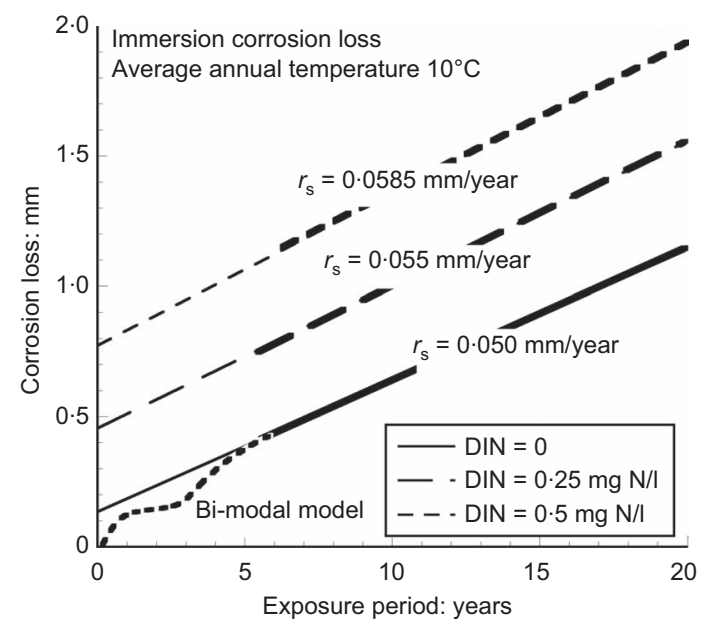

Figure 10. Linear corrosion loss trends as functions of exposure period for increasing dissolved inorganic nitrogen (DIN) concentrations for corrosion in waters at $10^{\circ} \mathrm{C}$ average temperature. The long-term corrosion rate $r_{\mathrm{s}}$ is shown for each trend. For reference the bi-modal model is shown for DIN $=0$

lower limits at $t_{\mathrm{e}}=0$ and 20 years each multiplied by $\mathrm{R}_{\mathrm{P}}$ corresponding to the value of DIN. The linear trends for DIN $=0.25$ and $0.5 \mathrm{mg} \mathrm{N} / 1$ are shown in Figure 10. The expected immersion corrosion losses at $t_{\mathrm{e}}=20$ years are $1 \cdot 14,1.55$ and $1.94 \mathrm{~mm}$ for $0,0.25$ and $0.5 \mathrm{mg} \mathrm{N} / 1$ of DIN, respectively.

The corrosion losses $A$ in the ALWC zone are estimated from $A=R_{\mathrm{A}} I$ where $R_{\mathrm{A}}$ is obtained from the correlation relationship $R_{\mathrm{A}}=1 \cdot 055+4 \cdot 5 N$ where $N$ is the concentration of DIN, shown in Figure 3. For DIN $N=0.25$ and $N=0.5 \mathrm{mg} \mathrm{N} / 1$ this gives the ALWC corrosion loss $A$ as follows

$$
\begin{aligned}
A\left(t_{\mathrm{e}}\right) & =[1.055+4 \cdot 5(0.25)] \times(1.55) \\
& =3.38 \mathrm{~mm} \text { for DIN }=0.25 \mathrm{mg} \mathrm{N} / 1 \\
A\left(t_{\mathrm{e}}\right) & =[1.055+4 \cdot 5(0.50)] \times(1.94) \\
& =6.41 \mathrm{~mm} \text { for } \mathrm{DIN}=0.50 \mathrm{mg} \mathrm{N} / 1 .
\end{aligned}
$$

\section{Discussion}

Figures 3 and 10 show clearly the effect of DIN on the longerterm corrosion loss of steel piling in seawater. Figure 10 shows the effect on immersion corrosion and Figure 3, through the multiplier $R_{\mathrm{A}}$, the additional effect on the localised corrosion in the region just below MLT (i.e. the ALWC effect). As noted, the major component of DIN is nitrates. Other components such as ammonia and nitrite usually oxidise quite quickly to nitrate, particularly in aerated and turbulent seawater. In many situations the major contributors to DIN are fertiliser runoff and sewage treatment effluents (or untreated sewage).
Conventional secondary sewage treatment does not remove nitrogenous matter, with the result that sewage plant effluent is a significant problem for many receiving waters, such as the North Sea (OSPAR, 2000). The immediate conclusion is that corrosion of unprotected steel infrastructure in seawater immersion conditions can be reduced considerably by the reduction of anthropological DIN water pollution. While the reduction of DIN into receiving waters may not be practical, politically feasible or cost effective, understanding the implications is a potentially important aspect for decisions regarding steel infrastructure and environmental and pollution controls.

Other possibilities proposed for reducing the immersion corrosion of steels in seawater include modification of the composition of the steel. For steel exposed mainly to clean seawater immersion conditions, changes in the composition of steel have shown, at least for coupons, markedly different effects for short-term and for long-term exposures, but overall the effects are small unless alloying is quite high (such as for stainless steels). Also, small additions of copper, chromium and nickel may increase longer-term immersion corrosion losses (Melchers, 2004b). This is consistent with well-established experience (Evans, 1960).

Data on the effect of alloying on full-size steel elements such as steel piles extending through the tidal zone are limited. One exception is for one carbon steel and six low alloy steel strips $300 \mathrm{~mm}$ (12 in) wide and $7 \mathrm{~m}$ (23 ft) long exposed for 5 years in the inter-coastal waterway adjacent to Harbor Island (NC, USA) (Larrabee, 1958). Figure 11 shows the corrosion profile for carbon (structural) steel obtained from coupons cut from the steel strips. It also shows the two extremes of the alloyed cases. Steel A is comparable in composition to Mariner steel (ASTM, 2013) usually claimed to be more suitable for steel sheet piling because of greater corrosion resistance. Figure 11 shows that compared to carbon steel, it has much greater corrosion resistance in the atmospheric zone but only slightly greater resistance in the immersion and tidal zones. Steel F, with higher phosphorus but lower nickel and copper, is somewhat beneficial in the atmosphere and the ALWC zone but is much more resistant in the immersion zone. How much of these results is the direct or indirect effect of water pollution is unclear. The water quality at this site is listed as subject to local sewage effluents. From US EPA documents (US EPA, 2012) it is estimated that for the period when the tests were conducted (mid-1950s) the DIN concentration was in the range $0 \cdot 06-0 \cdot 12 \mathrm{mg} \mathrm{N} / 1$.

A parallel experiment (Kumar et al., 1981) of 5-year exposure of structural steel piles and Mariner steel piles at Buzzards Bay (MA, USA) showed a generally similar response (Figure 12). These results can be attributed to the higher copper content ( $0 \cdot 5 \%$ minimum by weight) in A690 compared with most 




Figure 11. Effect on corrosion loss profile through the immersion and tidal zones of small changes in steel composition. Steel $\mathrm{A}$ corresponds closely to Mariner steel (A690). Cu, copper; Ni, nickel; $\mathrm{P}$, phosphorus. Based on data reported by Larrabee (1958)

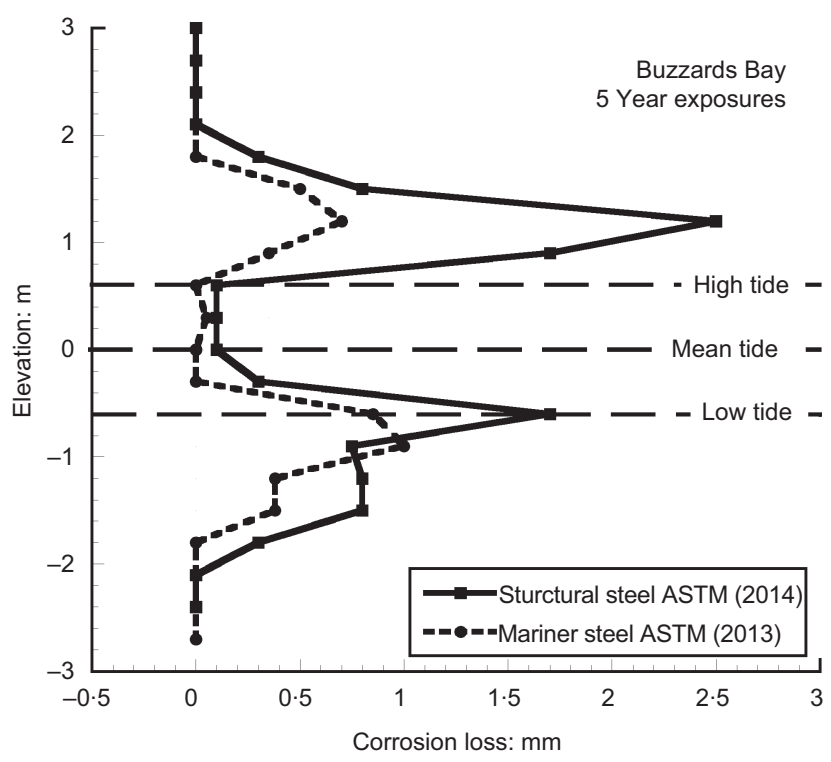

Figure 12. Effect on corrosion loss profile through the immersion and tidal zones for structural steel (A36) and Mariner steel (A690). Based on data reported by Kumar et al. (1981) structural steels, consistent with expectations from coupon experiments (Evans, 1960).

Guidance on the most appropriate protection system, such as cathodic protection and protective coatings, is available for piling (Breakall, 2011; Breakall et al., 2005). Figure 13 shows an example of sacrificial zinc anode applied to structural steel piles. Cathodic protection can be very effective in the immersion zone but not in the tidal and in the splash zones. In these regions only protective coatings are effective. Test results for the effectiveness of various protective coatings over 5 years' exposure are available (Kumar et al., 1981).

For protection systems to be effective and to remain effective it is essential that they be applied from the very beginning of exposure. In addition, for protective coatings surface preparation should be of high quality. Poor or inadequate surface preparation is a major cause of the early failure of protective coatings (Evans, 1960). In addition, maintenance of surface coatings is critical because once a coating begins to fail and corrosion starts, it is very difficult to stop. This applies even with intensive and expensive blasting to remove previous rusts. One of the main reasons is that not all previous microscopic pitting can be removed except with major removal of steel, and any pits left in a surface will be the starting points of any future corrosion and blistering of protective coating (Evans, 1960).

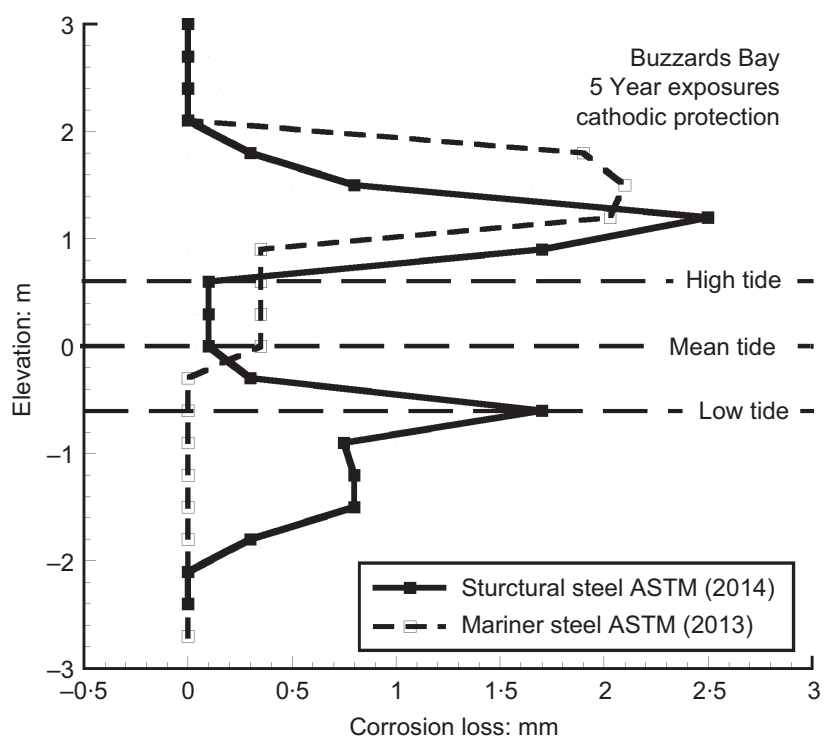

Figure 13. Corrosion profiles for structural steel through the tidal zone showing the significant positive effect of sacrificial anode cathodic protection (using zinc anodes) in the immersion zone but the limited effect in the tidal and splash zones. Based on data reported by Kumar et al. (1981) 
An important practical implication of the present work is that for the design of steel maritime structures without cathodic protection or protective coatings, or both, account must be taken of the level of nutrient pollution in determining likely corrosion losses and minimum sacrificial corrosion allowances. In addition, as shown in Figure 6, the conventional notion of an average 'corrosion rate' is inadequate to represent the progression of long-term corrosion. A more satisfactory representation for predicting long-term corrosion loss considers a long-term rate $r_{\mathrm{s}}$ together with the parameter $c_{\mathrm{s}}$, as shown in Figure 6 . The conventional corrosion rate invariably overestimates future long-term corrosion and thus may contribute to unnecessary or premature replacement or demolition. Standard documents (such as BS 6349 (BSI, 2010)) should be modified to take these matters into account.

\section{Conclusion}

For the prediction and representation of long-term immersion corrosion of steel corrosion, loss should be represented by a bilinear model rather than the conventional corrosion rate. The long-term rate is influenced by microbiological influences as identified previously in both laboratory and field investigations. These also showed that DIN is a nutrient critical to controlling the rate of microbiological metabolism and thus corrosion. In this paper field data from a variety of sources show that the long-term immersion corrosion of steel piling exposed to natural coastal seawaters is increased by the presence, in the waters surrounding the steel, of DIN resulting from water pollution, usually from anthropological sources. This also applies to so-called ALWC, corrosion that occurs in the region just below low tide level. These relationships are quantified, allowing predictions to be made both of the likely severity of immersion corrosion and of ALWC. An illustrative example is given. The effects of steel composition and cathodic protection are described and the relative role of protective coatings is outlined.

\section{Acknowledgements}

The support of the Australian Research Council in providing an Australian professorial fellowship and supporting research funds is acknowledged with gratitude. The authors also acknowledge the support of Fisheries NSW (Taylors Beach) and the Royal Australian Navy (Jervis Bay) for facilitating long-term corrosion field tests.

\section{REFERENCES}

Anon. (2008) Piling Handbook, 8th edn. ArcellorMittal, Luxembourg.

Arup HH and Glantz G (1963) An evaluation of corrosion of sheet steel piling in Danish harbors. Proceedings of the 2nd International Congress on Metallic Corrosion, 11-15 March. National Association of Corrosion Engineers, New York, NY, USA, pp. 424-431.
ASTM (2013) A690 / A690M-13a, Standard specification for high-strength low-alloy nickel, copper, phosphorus steel Hpiles and sheet piling with atmospheric corrosion resistance for use in marine environments. ASTM International, West Conshohocken, PA, USA.

ASTM (2014) A36 / A36M-14, Standard specification for carbon structural steel. ASTM International, West Conshohocken, PA, USA.

Beech IB and Campbell SA (2008) Accelerated low water corrosion of carbon steel in the presence of a biofilm harbouring sulphate-reducing and sulphur-oxidising bacteria recovered from a marine sediment. Electrochimica Acta 54(1): 14-21.

Breakall JE (2011) Selecting a strategy for dealing with accelerated low water corrosion (ALWC): Parts 1 and 2. Port Technology International Feb: 52-54, 56-57.

Breakall JE, Foster K and Siegwart M (2005) Management of Accelerated Low Water Corrosion in Steel Maritime Structures. Ciria, London, UK, Report C634.

Brouillette CV and Hanna AE (1960) Corrosion Survey of Steel Sheet Piling. Technical Report R-097. US Naval Civil Engineering Laboratory, Port Hueneme, CA, USA, 63 pp.

BSI (2010) BS 6349-2:2010: Maritime works. Code of practice for the design of quay walls, jetties and dolphins. BSI, London, UK.

Christie J (2001) Concentrated corrosion on marine steel piles A practical introduction. Port Technology International 13: 93-96.

Crolet J-L (1992) From biology and corrosion to biocorrosion. In Microbial Corrosion (Sequeira CA and Tiller AK (eds)). The Institute of Metals, London, UK, pp. 50-60.

Dean SW and Reiser DB (2002) Analysis of long-term atmospheric corrosion results from ISO CORRAG program. In Outdoor Atmospheric Corrosion, STP 1421. ASTM, West Conshohocken, PA, USA, pp. 3-18.

Escalante E, Iverson WP, Gerhold WF, Sanderson BT and Alumbaugh RL (1977) Corrosion and Protection of Steel Piles in a Natural Seawater Environment. National Bureau of Standards Monograph 158, US Government Printing Office, Washington, DC, USA.

Evans UR (1925) Water-line corrosion of iron and steel, with special reference to the addition of the so-called "inhibitors" of corrosion. Journal of The Society Chemical Industry 44(15): 163-169.

Evans UR (1960) The Corrosion and Oxidation of Metals: Scientific Principles and Practical Applications. Edward Arnold, London, UK.

Forgeson BW, Southwell CR and Alexander AL (1960) Corrosion of metals in tropical environments - Part 3 - Underwater corrosion of ten structural steels. Corrosion 16(3): 105t$114 \mathrm{t}$.

Gubner R and Beech IW (1999) Statistical Assessment of the Risk of Accelerated Low-Water Corrosion in the Marine 
Environment, Corrosion '99. NACE International,

Houston, TX, USA, Paper 318.

Hou W and Liang C (2004) Atmospheric corrosion prediction of steels. Corrosion 60(3): 313-322.

Humble HA (1949) The cathodic protection of steel piling in seawater. Corrosion 5(September): 292-300.

Kumar A, Lampo R and Beitelman A (1981) Corrosion Control of Pilings in Seawater: Buzzards Bay. Construction Engineering Research Laboratory, United States Army Corps of Engineers, Champaign, IL, USA, Technical report M-286.

Jeffrey R and Melchers RE (2003) Bacteriological influence in the development of iron sulphide species in marine immersion environments, Corrosion Science 45(4): 693-714.

LaQue FL (1951) Corrosion Testing, Edgar Marburg Lecture. Proceedings ASTM 51: 495-582.

Larrabee CP (1958) Corrosion-resistant experimental steels for marine applications. Corrosion 14: 501t-504t.

Lee JS, Ray RI and Little BJ (2010) The influence of experimental conditions on the outcome of laboratory investigations using natural coastal seawaters. Corrosion 66(1): 15001-1-6.

Lee W, Lewandowski Z, Nielsen PH and Hamilton WA (1995)

Role of sulfate-reducing bacteria in corrosion of mild steel: A review. Biofouling 8(3): 165-194.

Little BJ and Lee JS (2007) Microbiologically Influenced Corrosion. Wiley, Hoboken, NJ, USA.

Martin JH, Coale KH and Johnson KS (1994) Testing the iron hypothesis in ecosystems of the equatorial Pacific Ocean. Nature 371(6493): 123-129.

Melchers RE (2003a) Modeling of marine immersion corrosion for mild and low alloy steels - Part 1: Phenomenological model. Corrosion 59(4): 319-334.

Melchers RE (2003b) Mathematical modelling of the diffusion controlled phase in marine immersion corrosion of mild steel. Corrosion Science 45(5): 923-940.

Melchers RE (2003c) Modeling of marine immersion corrosion for mild and low alloy steels - Part 2: Uncertainty estimation. Corrosion 59(4): 335-344.

Melchers RE (2004a) Pitting corrosion of mild steel in marine immersion environment - 1: Maximum pit depth. Corrosion 60(9): 824-836.

Melchers RE (2004b) Effect of small compositional changes on marine immersion corrosion of low alloy steel. Corrosion Science 46(7): 1669-1691.

Melchers RE (2005) Effect of nutrient-based water pollution on the corrosion of mild steel in marine immersion conditions. Corrosion 61(3): 237-245.

Melchers RE (2007a) The effects of water pollution on the immersion corrosion of mild and low alloy steels. Corrosion Science 49(8): 3149-3167.

Melchers RE (2007b) The influence of seawater nutrient content on the early immersion corrosion of mild steel -1 . Empirical observations. Corrosion 63(1): 318-329.
Melchers RE (2010) Experiments, science and intuition in the development of models for the corrosion of infrastructure. Corrosion and Materials 35(3): 24-41.

Melchers RE (2013) Influence of dissolved inorganic nitrogen on accelerated low water corrosion of marine steel piling. Corrosion 69(1): 95-103.

Melchers RE and Jeffrey R (2008) The critical involvement of anaerobic bacterial activity in modelling the corrosion behaviour of mild steel in marine environments. Electrochimica Acta 54(1): 80-85.

Melchers RE and Jeffrey RJ (2012) Corrosion of long vertical steel strips in the marine tidal zone and implications for ALWC. Corrosion Science 65(December): 26-36.

Melchers RE and Jeffrey RJ (2013) Accelerated low water corrosion (ALWC) of steel piling in harbours. Corrosion Engineering Science and Technology 48(7): 496-505.

Melchers RE and Wells PA (2006) Models for the anaerobic phases of marine immersion corrosion. Corrosion Science 48(7): 1791-1811.

OSPAR (2000) Regional Quality Status Report II for the Greater North Sea. OSPAR Commission for the Protection of the Marine Environment of the North-East Atlantic, London, UK. See http://www.ospar.org/eng/doc/pdfs/r1c4.pdf (accessed 03/12/2014).

Schumacher M (1979) Seawater Corrosion Handbook. Noyes Data Corporation, Park Ridge, NJ, USA.

Southwell CR, Forgeson BW and Alexander AL (1958) Corrosion of metals in tropical environments - Part 2 - Atmospheric corrosion of ten structural steels. Corrosion 14(9): 53-59.

Stineman RW (1980) A consistently well-behaved method of interpolation. Creative Computing 6(7): 54-57.

US EPA (US Environmental Protection Agency) (2012) Storet Central Warehouse. US EPA, Washington, DC, USA. See http://ofmpub.epa.gov/storpubl/dw_pages.querycriteria (accessed 05/12/2014).

\section{WHAT DO YOU THINK?}

To discuss this paper, please email up to 500 words to the editor at journals@ice.org.uk. Your contribution will be forwarded to the author(s) for a reply and, if considered appropriate by the editorial panel, will be published as discussion in a future issue of the journal.

Proceedings journals rely entirely on contributions sent in by civil engineering professionals, academics and students. Papers should be 2000-5000 words long (briefing papers should be 1000-2000 words long), with adequate illustrations and references. You can submit your paper online via www.icevirtuallibrary.com/content/journals, where you will also find detailed author guidelines. 